\section{Entre fetichismo e sobrevivência: o artigo científico é uma mercadoria acadêmica?}

\author{
Between fetishism and survival: are scientific \\ articles a form of academic merchandise?
}

\author{
1 Escola Nacional de Saúde \\ Pública Sergio Arouca, \\ Fundação Oswaldo Cruz, \\ Rio de Janeiro, Brasil. \\ 2 Departamento de \\ Enfermería Comunitaria, \\ Medicina Preventiva y \\ Salud Pública e Historia de \\ la Ciencia, Universidad de \\ Alicante, Alicante, España. \\ 3 Red de Malnutrición \\ en Iberoamérica-CYTED \\ (Programa Iberoamericano \\ de Ciencia y Tecnología para \\ el Desarrollo). \\ Correspondência \\ L. D. Castiel \\ Departamento de \\ Epidemiologia e Métodos \\ Quantitativos em Saúde, \\ Escola Nacional de Saúde \\ Pública Sergio Arouca, \\ Fundação Oswaldo Cruz. \\ Rua Leopoldo Bulhões 1480, \\ Rio de Janeiro, $R J$ \\ 21041-210, Brasil. \\ luis.castiel@ensp.fiocruz.br
}

\begin{abstract}
This article discusses the possible meanings of the intense prevailing concern in academic circles over the notion of research productivity, as reflected in an excess number of articles published in various scientific journals. The numerical accounting of articles published by researchers in scientific journals with renowned academic status serves to legitimize academics in their fields of work, in various ways. In this sense, we suggest that scientific articles take on aspects of merchandise-as-fetish, according to Marx's theory of use-value and exchange-value and Benjamin's exposure value. Meanwhile, the biological notions of selection and evolution are used as metaphorical elements in "bibliographic Darwinism". There are references as to the possibility many of the prevailing bibliometric concerns serve as instruments for econometric analysis, especially to orient and enhance cost-effectiveness analysis in research investments of various orders and types, from the point of view of their economic return.
\end{abstract}

Journal Article; Periodicals; Scientific Communication and Diffusion
Luis David Castiel 1

Javier Sanz-Valero 2

Red MeI-CYTED 3

\section{Introdução}

Há indicadores bibliométricos que sinalizam para mudanças dramáticas no panorama da pesquisa científica nos últimos 10-15 anos. Se, por um lado, mais de $70 \%$ da produção mundial pertence ao eixo Estados Unidos/Comunidade Européia/Japão, há crescimentos espetaculares em alguns países em especial (como China e Irlanda, os mais significativos) e declínio em outros (GrãBretanha). Na América Latina, dados recentes mostram que a produção da ciência brasileira se destaca em seu crescimento de $8 \%$ na repartição do produto anual em termos mundiais e ocupa o 17o lugar na lista de países mais ativos. Talvez mais significativo seja o fato de ocupar o 9o lugar entre os países que apresentam maior dinamismo em termos percentuais de crescimento entre os anos 1991 a 2003, adiante da Espanha (11으) e onde se destacam sobremaneira Coréia do Sul, Turquia e Singapura 1 .

Sem dúvida, as análises acima mencionadas merecem a devida atenção quando se trata de descrever e comparar a produção científica e seus fluxos em múltiplos níveis de abrangência, tanto em termos globais como locais. Porém, tais dados necessitam de ser contextualizados em função não apenas de aspectos bibliométricos regionais e nacionais. É importante também levar em conta especificidades de caráter sóciohistórico no desenvolvimento das disciplinas e dos campos de produção de conhecimento em 
relação às transformações estruturais em aspectos políticos e econômicos que ocorreram nas últimas décadas.

Inegavelmente, a adoção de recursos informáticos e a existência da Internet viabilizaram uma impressionante difusão e uma concomitante ampliação das possibilidades de acesso à produção acadêmica. Com esses recursos, como se sabe, é cada vez mais acessível pesquisar e obter fontes bibliográficas, utilizar bancos de informações, analisar dados e redigir artigos científicos. Em geral, convive-se com a impressão de haver se tornado bem menos atribulada a produção de projetos e, caso sejam obtidos financiamentos, a realização de pesquisas. Mas, esta maior disponibilidade investigatória não ocorre sem efeitos colaterais indesejados.

Há um aumento considerável na disputa por recursos para a pesquisa e diminuição de recursos públicos para tanto ${ }^{2}$. Um dos requisitos para aceder aos financiamentos é a demonstração da produtividade dos grupos de pesquisa, sobretudo em termos de publicação nos veículos acadêmicos de melhor reputação nos respectivos campos. Assim, a competição se estende à luta ferrenha entre artigos que buscam a ocupação de espaços editoriais - o escoadouro almejado para os resultados dos esforços investigativos, mas também da necessidade de manutenção das esferas de prestígio e influência 2 .

Não é despropositada a impressão de haverse desencadeado um processo aparentemente irreversível e, talvez, no limite, incontrolável. Isso parece estar se tornando algo cada vez mais incidente nos meios acadêmicos, em geral, e no campo da pesquisa em saúde pública em particular 3 . A perspectiva aqui adotada se dirige à análise dos possíveis significados de um fenômeno que se manifesta neste contexto de ampliação na pesquisa científica e da intensa contabilização numérica de artigos publicados por investigadores em revistas científicas de reconhecido status acadêmico para se legitimarem como profissionais nos seus campos de atuação.

Com a enorme ampliação do número de revistas e artigos, não à-toa começa-se a conviver com a sensação de haver algo de desarrazoado diante desta cornucópia de artigos científicos. Ela se dá, a um só tempo, não só em quantidades enormes e de forma acelerada, mas também apresentando, embutida em sua proliferação, uma perspectiva duvidosa quanto à avaliação da respectiva fertilidade nos processos de construção do conhecimento em saúde pública ${ }^{4}$. Tal panorama não parece se refletir proporcionalmente em melhorias correspondentes nos quadros sanitários - como se houvesse uma desmesurada produção acadêmica que mal altera a precariedade da situação em saúde de muitos rincões deste mundo.

Apesar de a literatura especializada ser mais acessível, é cada vez mais laborioso ler-se o que é publicado nos correspondentes âmbitos de interesse. O ideal da atualização nas respectivas áreas parece ter se tornado algo cada vez mais difícil de ser alcançado no dia a dia. Assim, existem (e existirão) muitos artigos que jamais serão lidos. Este dado é difícil de ser estimado. Há, todavia, estimativas de que cerca de $50 \%$ dos trabalhos em ciências sociais publicados jamais serão citados 5 .

Há termos críticos, até jocosos, que designam esta ordem de questões éticas diante do fenômeno de proliferação na literatura científica. Alguns mais conhecidos, como "ciência-salame": uma pesquisa é fatiada em unidades menores publicáveis para se tornarem vários artigos distribuídos em diferentes revistas 6. Outros menos comuns como "publicacionismo" 7 e "produtivite" 8 começam a ser utilizados para designar tal quadro.

Em outras palavras: um mesmo conteúdo pode aparecer em vários artigos, após receber pequenas mudanças cosméticas. A autocitação pode constituir-se no chamado "autoplágio" 9. Já há revistas que solicitam na declaração que se costuma fazer na entrega dos originais um item especificando não se tratar de publicação redundante 10 . Outro aspecto importante seria se o artigo traz algo ao conhecimento ou à discussão científica, isto é, se é pertinente, relevante e "revelante" 11.

As questões éticas na pesquisa científica não são de forma alguma negligenciáveis. Em termos mais específicos, pode haver vários tipos de má-conduta e fraudes no meio científico, como o gerenciamento dos protocolos, amostragens e dos dados em geral 12. Ademais, há um crescente aumento de autores por artigo, significando mais do que o suposto aumento dos integrantes dos grupos de pesquisa, mas sim a possível prática de "escambo autoral" (meu nome no teu artigo, teu nome no meu artigo etc.) 13 .

A própria presença do plágio se torna algo mais praticável e difícil de ser percebido - ainda que sejam "microplágios" -, viabilizados pela cópia de trechos de textos disponíveis na Internet 14 . Não parece ser incomum a prática de autores, ao utilizarem uma determinada referência consultada e indicada no próprio artigo destes autores, também citarem outra(s) referência(s) presente no artigo citado como citação de seu próprio artigo, sem haver a consulta específica de tal referência. Sem dúvidas, a tarefa de editar revistas científicas se tornou bastante comple- 
xa ao envolver intrincados e múltiplos aspectos éticos.

Cabe ainda assinalar que, ao lado do "publicacionismo", convive-se com outro fenômeno acadêmico: o "citacionismo" - a grande importância do ato de citar outros autores e de ser-se citado em artigos -, que é em grande parte um efeito do êxito dos indicadores de impacto desenvolvidos pelo Institute for Scientific Information/ Thomson Scientific (ISI). Essa excessiva preocupação tornou-se, de certa forma, representativa do espírito de "avaliações rápidas" de nossos tempos modalizados na ambiência acadêmica. Aliás, a etimologia dos adjetivos latinos " $c i t u s, c i$ ta, citum" é emblemática ao indicar "posto em movimento", "vivo", "pronto", "rápido", "ligeiro”. É preciso produzir artigos que gerem citações, ou seja, que sejam publicados e tenham vitalidade para estarem presentes nas outras publicações.

\section{II}

A ciência é, sem dúvidas, uma tecnologia intelectual capaz tanto de gerar excelentes entendimentos e interpretações acerca do mundo, como de proporcionar intervenções e criação de objetos técnicos de maneira a corresponder a muitos projetos humanos; contudo, conforme mencionado, surge um problema sério com a ideologia da cientificidade. Vale dizer, em termos bastante abreviados, quando se considera que a ciência é o melhor modelo (em casos mais radicais, é considerada o único) para se compreender e representar o mundo e os homens 15 .

A força da ciência provém do fato de que seus protocolos, instrumentos e dispositivos de análise simplificam suficientemente a "realidade" com a finalidade estudá-la e atuar sobre ela. E, como presenciamos ao nosso redor, isso costuma acontecer de modo bastante eficaz. Mas o que está sob o guarda-chuva chamado ciência também pode cometer abusos de saber. Por exemplo, quando se pretende deduzir normas de conduta baseadas em unívocas evidências (pesquisas) científicas. Ou, então, reduzir problemas somente à sua tradução em termos técnicos 15 .

Latour abordou a suposta transição de uma cultura da "ciência" rumo à cultura da "investigação". Entende-se a ciência como uma atividade fria, direta e objetiva e a investigação, por sua vez, seria acalorada, arriscada, geradora de outras implicações. Se a ciência põe um final aos caprichos das disputas humanas, a investigação cria controvérsias. Como mencionado, a ciência opera sob o manto da idéia de objetividade, tentando escapar tanto quanto seja possível dos supostos grilhões da ideologia, das paixões e das emoções; já a investigação é nutrida de todos esses aspectos para gerar perguntas de investigação menos afastadas de nós próprios. Podemos pensar que essas duas perspectivas básicas coexistem em graus variados na atividade científica atual 16 .

Levando adiante tal linha de raciocínio, um olhar científico puro é algo abstrato - como se aquilo que essencialmente definisse a atividade científica fosse a busca fidedigna de dados e a correspondente aplicação correta de protocolos, desenhos de investigação e análise dos resultados. Já existiu um imaginário social no qual o cientista era antes de tudo um benfeitor da humanidade 17 (este era o título de um livro lançado na década de 1940 para crianças com biografias de renomados cientistas) com qualidades nobres, entre outras. Por exemplo: desinteresse por coisas materiais em nível pessoal 18 , altruísmo. Tanto que em relação ao artigo científico já houve momentos poucas décadas atrás em que o cientista se comportaria como um doador ao entregar seus artigos a uma revista, e seria essa doação que o constituiria como cientista. Como retribuição receberia prestígio, como diz Hagstrom. A organização social da ciência consistiria em uma troca de reconhecimento social por informação 19. Parece haver, no entanto, indícios cada vez mais fortes de que muito desse imaginário estaria progressivamente se transformando.

\section{III}

Uma das atividades dos investigadores é gerar interesse em relação a seu objeto de estudo em diferentes níveis do processo de produção científica 20 - isso inclui despertar o interesse de revistas científicas para publicar artigos de sua linha de pesquisa. Em outras palavras, o pesquisador necessita também de administrar sua carreira profissional e seus vínculos e papéis no interior de equipes de investigação. A saber, existem outras dimensões que afetam o trabalho científico e envolvem relações de influência e jogos de poder entre instâncias e grupos de pesquisa.

Parece ser necessário esquadrinhar de modo mais contextual as várias atividades do pesquisador para além dos requisitos de objetividade $\mathrm{e}$ da manutenção do rigor científico na atividade científica, tais como: estratégias de busca de financiamento, gestão das relações entre grupos acadêmicos, comunicação entre pares (por isso, a suprema importância da padronização e da normalização nas práticas científicas), formas de produzir e ter sucesso na publicação de um número importante de artigos em revistas conceituadas no respectivo campo, ensejando, para o êxito se fazer manifesto, uma boa quantidade de 
citações. Vamos denominar este último aspecto de "bibliografia citaciogênica", no sentido específico e estrito os artigos capazes de geração do maior número possível de citações.

Um exemplo: Hackett estudou em laboratórios de biologia molecular as questões ligadas a ambivalências, tensões e paradoxos relativos a aspectos como: (1) o estabelecimento e manutenção de identidade do grupo e de cada pesquisador no interior do grupo; (2) a obtenção e sustentação de poder e controle nas relações entre pesquisadores diante do conjunto de tecnologias e práticas de pesquisa; (3) a escolha de riscos que pesquisadores estão dispostos a assumir em sua atividade em relação às possibilidades de resultados satisfatórios para a continuidade de suas linhas de investigação ${ }^{21}$. Claro que a preocupação citaciogênica está implacavelmente presente neste panorama.

Vejamos: um pesquisador optou por uma linha de pesquisa com teores mais altos de risco na obtenção de resultados diante de seus investimentos - um sistema para estudar eventos recombinantes em células humanas. Mas houve problemas de confounding em razão de artefatos metodológicos pelo uso da reação em cadeia da polimerase que pode provocar recombinação per si. O citado pesquisador abandonou esta linha e adotou outro rumo com outro conjunto de tecnologias de pesquisa centrada em ratos transgênicos, combinando biologia molecular, genética tradicional e manipulação de óvulos de ratas pseudográvidas. Este tampouco se mostrou recompensador. Tais malsucedidos processos interromperam suas fontes de financiamento e lhe obrigaram a mudar para outra universidade, onde começou outra linha de pesquisa mais próxima da medicina que da biologia básica. Os dados do Science Citation Index evidenciam a versão bibliométrica desta história - própria do espírito desta época citaciogênica:

Fase 1 (biologia básica - até dez anos depois da publicação): 7 artigos que receberam 37 citações;

Fase 2 (pesquisas biológicas de orientação biomédica - quatro anos depois do início das investigações): 5 artigos que receberam 211 citações 21 .

De modo bastante simplificado, no campo da saúde pública, todas estas dimensões pertencentes à "big science" parecem não se comportar, em geral, da mesma forma. Aparentemente, não há tantas pressões no sentido de novas descobertas ou da criação de produtos e tecnologias. As tensões parecem assumir outros aspectos - como, por exemplo, as premências instrumentais das questões de saúde pública e suas defasagens em termos de produzir estudos que permitam o conhecimento satisfatório das diversas formas como as tendências de morbidade, mortalidade e estados de risco e as correspondentes possibilidades de inserção destes conhecimentos em termos de práticas que conduzam a resultados efetivos de mudança na situação de saúde.

Conforme descreveu Coimbra Jr. 22, há que levar em conta, no caso da saúde pública latinoamericana, elementos suficientes para considerar que a utilização dos fatores de impacto do ISI produz um panorama parcial e deformado ao não perceber as especificidades do campo em relação aos “...impactos sobre políticas, planejamento de estratégias de intervenção e de programas de saúde, ou sobre a organização de serviços que muito extrapolam a mera quantificação de referências/citações bibliográficas" 22 (p. 887).

Mas, mesmo assim, as pressões publicacionistas em termos de local de publicação e impacto parecem ser onipresentes em todos os contextos. No outro corolário da afirmação acima, o fato de ser-se muito citado não quer necessariamente dizer avanço do conhecimento. Entretanto isso permanece uma das formas de aferir a suposta importância de um artigo. Inclusive, existem recursos informáticos que permitem o acompanhamento específico em termos de quem cita quem e onde, como por exemplo, o sistema Scopus (http://www.info.scopus.com/).

\section{IV}

Desde logo, um caminho imediato para pensarse a dimensão "mercadoria" de um artigo científico seria considerar que os preços pagos por interessados por aqueles trabalhos cujo acesso não é livre somente ocorrem mediante pagamento às editoras dos periódicos. Até porque há vários custos embutidos na confecção editorial de artigos por revistas. Por outro lado, há textos com acesso aberto na Internet, mas uma revisão bibliográfica consistente não pode abrir mão de artigos com acesso por meio de pagamento. Porém, esta é uma leitura limitada para o enfoque pretendido. De qualquer forma, é preciso salientar que as discussões "acesso livre versus acesso pago" são candentes e importantes, mas não se trata de objeto deste trabalho.

É cabível encarar um artigo científico sob a ótica sociológica da dinâmica das comunidades científicas - como resultado de uma linha de investigação que ao lado de sua produção científica também gera capitais simbólicos. Dando prosseguimento a este argumento, um artigo pode assumir determinados traços como se fossem mercadorias que estarão disponibilizadas em revistas científicas. Estas, por sua vez, são sele- 
tivas em sua capacidade de recusar determinados itens e selecionar outros sob critérios acadêmicos de controle de qualidade, aplicados por revisores também selecionados dentre autores consagrados no campo. Outrossim, também, a seletividade das revistas é regida por critérios de oferta e procura. Por exemplo, o BMJ informa aos autores que aí querem submeter seus trabalhos que apenas $12 \%$ dos 6.000-7.000 artigos submetidos anualmente são aprovados 23 .

Arranz 24 critica o espírito de "jogo" na publicação científica em função de um artigo do neozelandês Tim Albert 25 traduzido do inglês especialmente para ser publicado pela revista espanhola Gaceta Sanitaria. Nele, há uma receita de dez passos que lembram os manuais de auto-ajuda com conselhos para vencer no "jogo" de escrever artigos científicos. A vitória é tê-los publicados de preferência em revistas importantes. Há menção explícita que "se trata de uma atividade de venda" e que "a tarefa é criar um produto [o artigo científico] e vendê-lo ao cliente [o editor]" 25 (p. 355). Uma vez que este o compra (aceita para publicação), completa-se a transação e se resolve com sucesso a tarefa; logo está ganha a partida.

Nesse sentido, queremos sugerir que o jogo que se busca vencer é o "jogo" competitivo do mercado com elementos e regras compatíveis com a competitividade reinante em várias atividades do mundo atual. Para isso, é preciso ampliar a discussão acerca da dimensão mercadológica na publicização da atividade científica.

A autoria de artigos se tornou moeda corrente - uma mercadoria negociável no mercado acadêmico em tempos de grandes investimentos nas ciências biológicas e médicas ("big science"). Em outro contexto, o próprio Marx 26 (p. 81) indicou a dimensão do fetichismo da mercadoria ao indicar sua característica "misteriosa”: “...ao encobrir as características sociais do próprio trabalho dos homens, apresentando-as, como características materiais e propriedades sociais inerentes aos produtos do trabalho: por ocultar portanto a relação social entre os trabalhos individuais dos produtores e o trabalho total, ao refleti-la como relação social existente, à margem deles, entre os produtos de seu próprio trabalho. Através dessa dissimulação, os produtos do trabalho se tornam mercadorias, coisas sociais, com propriedades perceptíveis e imperceptíveis aos sentidos (...). Uma relação social definida, estabelecida entre os homens, assume a forma fantasmagórica de uma relação entre coisas. (...) É o que ocorre com os produtos da mão humana, no mundo das mercadorias. Chamo a isto de fetichismo, que está sempre grudado aos produtos do trabalho, quando são gerados como mercadorias".
Decerto seria um exagero detalhista argumentar que é necessária a adaptação destas idéias ao pensá-las no âmbito bibliográfico e alegar-se que não se trata exatamente de um produto da mão humana - no sentido original de manufatura, mas sim resultado da intervenção primordial do intelecto humano. Ainda assim, há um curioso dado lingüístico - no início de sua trajetória, logo após a confecção pelos autores, o artigo científico costuma receber o nome original de manuscrito, mesmo que na atualidade os textos sejam processados mediante recursos informáticos.

Realmente, importa destacar nesta breve análise do artigo como mercadoria a noção de valor de uso perceptível - relativo à utilidade específica deste "artigo" para seus consumidores/ leitores em relação à capacidade de contribuir para o que se supõe ser o avanço do conhecimento dentro do respectivo campo disciplinar. E é preciso, também, levar em conta seu valor de troca imperceptível, como fetiche no caso das trocas simbólicas - enquanto elemento capaz de ter agregadas certas "quantidades" de prestígio ou reconhecimento para seus autores. Tais componentes são essenciais para mantê-lo ativo e influente e ao grupo ao qual pertence no território de interações cooperativas e competitivas da comunidade científica em que atua.

Ainda, uma chave analítica promissora para abordar este aspecto é aquela proposta por Benjamin 27 na noção de "valor de exposição" referente ao estudo da obra de arte, mas que mutatis mutandis cabe ser aplicada também ao artigo científico. Se isso vale para a análise da divulgação da obra de arte, também parece valer para as formas de comunicação próprias às comunidades científicas, se encararmos a divulgação científica também como uma forma implícita de exibição de autores e linhas de pesquisa.

Os pesquisadores precisam publicar, seja por razões normativas definidas pela configuração dos necessários intercâmbios em rede que definem o avanço e o debate inerente à atividade científica, seja pela necessidade de mostrar-se produtivo aos olhares judiciosos daqueles que financiam pesquisas. Seguindo Agamben 28, há algo de espetacularização focal no interior das comunidades científicas, até porque consumo e espetáculo se constituem em elementos essenciais na fase extrema do capitalismo que estamos vivendo, e a ciência parece não ter como escapar dos efeitos desse processo.

A perspectiva que se está desenvolvendo pode também ser representada por intermédio de analogias darwinistas. A analogia com as idéias evolutivas darwinianas em história das ciências e epistemologia não é original. Thomas Kuhn 29 
considerava que sua idéia de evolução das idéias científicas se assemelhava às teorias de Darwin sobre a evolução de organismos. E, ainda, são usadas comparações biológicas diante do surgimento ou desaparecimento nos contextos editoriais 30 .

Logo, não é absurdo pensar que o conhecido lema "publicar ou perecer" implica algo parecido com as lutas territoriais para a seleção dos mais aptos entre artigos que lutam entre si. Primeiramente, para despertarem o interesse e a atenção dos editores como tema relevante e importante no âmbito acadêmico; depois, serem devidamente analisados para obedecerem às demandas dos revisores em busca da ansiada chancela de qualidade que conduz à meta da aprovação para a publicação. Este é um prêmio depois da ultrapassagem por esses controles, pois isso significaria a possibilidade de habitar nichos mais valorizados deste mercado, algo que poderia ser chamado de "darwinismo bibliográfico".

Há, ainda, outras recompensas a alcançar: a luta continua com o objetivo de propagação, por meio da legitimação pela sua respectiva comunidade - as valiosas citações pelos pares. As citações são valorizadas a tal ponto, que existem sistemas de classificação (que pode até se dar em um hit parade de acesso a trabalhos específicos em sites de revistas) 31,32 em rankings de artigos cujos autores foram bem sucedidos nesse item.

No caso da análise dos significados dos artigos científicos, Velho ${ }^{33}$ reforça a perspectiva de artigo como mercadoria. Para ele, a cienciometria bibliométrica propõe a atividade científica como um processo no qual certos insumos ou recursos geram determinados produtos. Medir o impacto consistiria em estabelecer a relação insumo/produto. A questão consiste em instituir indicadores de insumos e de produtos. É bem mais difícil medir os produtos, sobretudo no que se refere aos efeitos dos conhecimentos produzidos e seus vínculos com a sociedade. Em geral, esses produtos são mensurados por indicadores bibliométricos que instauram nexos entre literatura científica, resultados de pesquisas e repercussões internas ao campo (como a citação em outros artigos), muitas vezes sem relação direta (e tampouco indireta) com questões societárias e do mundo da vida das pessoas 33 .

A imagem predominante do autor de artigos científicos está deixando de ser a do "gênio romântico" que dedica sua inteligência e capacidade de análise para propor formas de inquirir mistérios do mundo para benefício humano. Também deixa de ser a de um "funileiro" que desenvolve melhores formas de descrever entidades ou aperfeiçoar processos já existentes. Agora, grande parte dos autores inclui aqueles que atuam como "empregados" de empresas, funcionários que se dedicam a seguir a rotina de protocolos estabelecidos em propostas de investigação aceitas pelas agências financiadoras e consagradas pela comunidade científica. Eles também se dedicam às atividades burocráticas que envolvem o métier científico: fazer buscas de literatura, manter o relacionamento com outras instâncias e grupos de pesquisa, produzir esboços de artigos, apresentar pedidos de financiamento, revisar textos e materiais, além de participar nos intentos de publicar os artigos do grupo 34 .

Por sua vez, os líderes de grupos de pesquisa, para além de sua expertise técnico-científica, passam a atuar cada vez mais como homens de negócios ao gerenciar insumos, produtos, pessoal, recursos humanos, equipamentos, mas, sobretudo, devem manter ativas as fontes de financiamento para dar continuidade à sobrevivência de seu grupo, que é uma forma de manter a sua própria existência no campo.

Uma ilustração dos interesses privados envolvidos no plano dos artigos com maior número de citações na pesquisa do campo biomédico pode ser observado no meticuloso estudo sobre a análise das fontes de financiamento de tais artigos no período 1994-2003. Os resultados mostraram que dos 289 artigos investigados, o financiamento público era o mais comum (60\% dos artigos); a iniciativa privada era responsável por $36 \%$. A proporção dos artigos mais freqüentemente citados financiados pela indústria elevou-se ao longo do tempo e era igual à proporção daqueles financiados pelo setor público em 2001. Dos 77 ensaios clínicos aleatorizados mais citados, 65 foram financiados pelo setor privado e a proporção aumentou significativamente ao longo do tempo. Dos 32 mais citados ensaios clínicos publicados depois de 1999, somente 18 foram financiados pela indústria 35 .

Um importante elemento neste quadro se localiza no crescimento das contract research organizations (CRO) - organizações não-governamentais que se dedicam a conduzir pesquisas, funcionando como "empreiteiras" contratadas pelas indústrias farmacêuticas para realizar investigações com menores custos e mais rapidamente. Em 2000, as CRO já recebiam $60 \%$ de todos os recursos para pesquisa farmacêutica 36 .

\section{V}

Os pesquisadores podem ser encarados como agentes que adotam posturas tanto de fabricantes como de consumidores de artigos que competem entre si para chamar a atenção em 
meio a um mar de "papers". Em ambos os casos, é preciso assinalar aspectos relativos às dificuldades na aceitação de trabalhos em revistas mais prestigiadas, nas quais se pressupõe a ação de filtros mais estreitos na seleção de artigos - algo que pode agregar mais valor ao fato de aí serem publicados.

Em geral, a grande maioria destas revistas publica no idioma inglês e pertence a contextos em que a produção científica é mais desenvolvida (Comunidade Européia e Estados Unidos). Como existe nesses âmbitos uma valorização de abordagens empíricas e objetos e temas pertencentes aos respectivos contextos de pesquisa em saúde, a aceitação de artigos acaba por refletir tais padrões. Ou seja, existem temáticas e abordagens que são mais capazes de gerar interesse e de serem, portanto, aceitas por revistas de mais prestígio.

No nível das revistas, sob uma perspectiva similar, há uma hierarquia de supremacia. Da mesma maneira, existe um ranking dos periódicos de acordo com o fator de impacto - que desfruta de uma considerável aceitação em sua capacidade de descrever contabilmente o panorama de autores e revistas, apesar de ser encarada por muitos como uma medida de quantificação criticável em seu fetichismo numérico ao gerar pontuações descontextualizadas, obtidas por meio de citações de seus artigos 37. Além disso, é inegável que, mesmo com todas as precauções éticas, pode haver um poder editorial sendo exercido nas revistas mainstream ao implicitamente defenderem interesses às vezes justificados, mas eventualmente nem tanto, ao se aceitarem determinados artigos em detrimento de outros em nome da "boa ciência" 38 .

Em outra escala, a competitividade é mimetizada no âmbito da relação entre revistas e indexadores. Há também uma competição entre revistas que buscam manter seus respectivos prestígios - que pode ser dimensionado por sua capacidade de receber a chancela de indexadores consagrados (em geral, anglo-saxônicos, com destaque para o MEDLINE e o ISI), após duras provas (um dos requisitos é o fator de impacto) para ser aceita e preencher os requisitos para manter tal posição.

Em editorial, os editores da revista espanhola Gaceta Sanitaria, ainda que declarem uma eqüidistância em sua posição entre impactofobia e impactofilia, adotam uma posição "pragmática" quanto à importância das citações. E não têm pudor para pedir citações desta revista para efeitos de futura indexação no Science Citation Index do ISI 39 .

Há instâncias especializadas em produzir rankings bibliométricos que são administrados pela Thompson Corporation em cujos sites podem-se acessar classificações de desempenho acadêmico em termos quantitativos correspondentes a nomes, revistas, instituições e países por campo disciplinar - por tratar de pesquisa básica, infelizmente nem saúde pública, nem epidemiologia aparecem. Por exemplo: http:// isihighlycited.com; www.sciencewatch.com; e http://in-cites.com/. Em todos há classificações de variados tópicos, formatos e categorias, inclusive os "trabalhos mais citados", chamados "artigos mais quentes" (hottest papers) da temporada, como se acompanhassem o comportamento no terreno dos modismos transitórios no contexto do "consumo" usual, a ponto de merecer a mesma metáfora relativa ao respectivo êxito.

Conforme enuncia o site http://in-cites. com, os objetivos explícitos desses rankings é o de "analisar o desempenho de empresas, instituições e revistas; classificar países, revistas, cientistas, instituições e empresas por campo de pesquisa; identificar tendências significativas nas ciências e ciências sociais; avaliar potenciais empregados, colaboradores, pareceristas [reviewers] e colegas [peers]; determinar produtos [outputs] de pesquisa e impacto em campos específicos de pesquisa" 40.

Trata-se de um instrumento de análise de caráter eminentemente econométrico para, sobretudo, orientar e maximizar análises de custo-efetividade em investimentos em pesquisa de várias ordens e tipos sob o ponto de vista de seu retorno econômico. Isto fica claro na discriminação dos potenciais usuários dessas informações: "policymakers do governo, administradores de pesquisa de universidades ou de empresas; analistas pesquisadores ou especialistas em informação no governo, academia, indústria, setor de publicações, serviços financeiros e fundações de pesquisa" 40. Aqui, chegamos à conhecida e inevitável pergunta própria à crítica dos sistemas hierárquicos de controle e vigilância: e quem indexa os indexadores? Pelo visto, tais instâncias exercem suas atividades e impelem seus padrões e difundem a presente ideologia bibliométrica aparentemente sem maiores resistências, alimentando a cornucópia de produção científica.

\section{Considerações finais}

Os cientistas, disseram Latour \& Woolgar 41 há quase três décadas, são como corporações, e seu curriculum vitae é como um relatório de balanço empresarial. A autoria significa capacidade de dispor de créditos em termos de capital científico que podem ser acumulados e reinvestidos a fim de sustentarem o trabalho de alguém, para 
pedidos de financiamento a novas pesquisas e/ ou para trabalhos posteriores aceitos. Os créditos utilizados com sabedoria são aqueles que respondem efetivamente às leis de oferta e procura. Neste modelo, cientistas são ao mesmo tempo empregadores (empresas) e empregados: suas fontes de financiamento permanecem como poder derradeiro neste mercado, sobre o qual possuem poder limitado. Por conseguinte, o artigo científico é uma das formas principais de capital científico com poder de gerar mais capital 42 .

Por mais que não haja consenso em relação a perspectivas teóricas nas proposições de estudar a participação da academia no processo de comercialização da pesquisa científica, há autores que sugerem que tal fenômeno teria começado em várias frentes no início da década de 1980 33, quando aconteceu uma evidente inflexão no aumento da pesquisa científica, coincidentemente a ocasião em que começa o desenvolvimento de recursos informáticos e telemáticos - o computador pessoal e a Internet 43 .

Nosso ponto de vista ressalta que no âmbito da publicação científica a comercialização da pesquisa científica se manifesta pela progressiva mercadorização do objeto "artigo científico". Como foi discutido antes, há uma dimensão importante neste sentido diante das transações para entrar-se no "mercado" das comunidades científicas fortes. Neste caso, quais são as negociações entre autores, editores, revisores para além de obedecer aos "aspectos técnico-científicos" no juízo de um artigo, isto é, elementos extracientíficos e seus limites biblioéticos nas ações e concessões que pesquisadores permitem fazer para publicar seus artigos e para aceitar os de outrem? Colocar como referência bibliográfica trabalhos publicados no mesmo periódico onde se tenta publicar? Não consultar as fontes bibliográficas ao copiá-las das referências de outros autores?

A preocupação com a detecção e o combate das práticas científicas que se desviam dos trilhos éticos e mediante controles para regular o empreendimento científico não se mostra um caminho suficiente para lidar com os excessos do panorama atual. As tentativas de controle correm o risco, elas mesmas, de se tornarem também excessivas. Importa produzir chaves analíticas que permitam a compreensão dos sentidos e significados da atividade científica nessa era prolífera em fluxos de informação em uma economia globalizada.

Cabe divisar os contextos acadêmicos de modo menos simplificador e limitado do que fazem rankings baseados em indicadores bibliométricos. Como se eles refletissem uma atividade "purificada" mediante suas propostas de mensuração da produção científica. As comunidades científicas parecem às vezes fiar-se em demasia em seus sistemas de regulação e de controle, como se assim pudessem estar efetivamente afastadas de influências de outros campos da atividade humana.

Apesar das dificuldades, são necessárias análises contextuais dos vetores e relações de poder que existem quando se publicam ou quando se fazem citações. Nesse sentido, importa desenvolver e adotar outras categorias que permitam ver o processo de produção de artigos a partir elementos para além de seus conteúdos acadêmicos explícitos. Tais categorias deveriam permitir a identificação de elementos que possam preencher os muitos vazios dos resultados de estudos bibliométricos 44 . Por exemplo, estudos etnográficos das negociações que ocorrem no processo editorial de uma revista desde a chegada de um artigo até o destino final, seja de recusa, seja de publicação.

A produção científica não tem somente o objetivo de gerar uma estratégia eficaz do que é possível ser feito, mas também consiste em uma vigorosa produção simbólica de caráter ideológico que não cessa de legitimar-se e motivar ações. Vigorosa porque parece pairar acima das ideologias. Sua indiscutível eficácia instrumental pode mascarar o funcionamento ideológico da ciência que é também uma atividade situada socialmente. Dessa forma, não se pode negligenciar a necessidade de dimensionar e compreender a participação da perspectiva universalizante da cultura científica no interior das propostas prevalentes na economia atual.

Como ocorre em muitos aspectos na produção e no consumo de mercadorias no capitalismo globalizado, parece haver algo equivalentemente excessivo no modo de produção e consumo de artigos científicos. Necessitamos de estudos que nos ajudem a compreender a origem, a dinâmica, os fluxos de poder e as respectivas redes pelas quais se movimentam bens, serviços, informação e conhecimentos que definem e controlam as definições do que seja a "realidade" da ciência. Tanto no sentido de distinguir aspectos benéficos e vantajosos para amenizar o sofrimento humano, como de propostas que naturalizam no cotidiano acadêmico as práticas do ideário neoliberal com implicações na manutenção e ampliação de seus efeitos de desperdício de vidas 45 ao sustentar iniqüidades sociais profundas. 


\section{Resumo}

Discutem-se possiveis significados da intensa preocupação vigente nos âmbitos acadêmicos com a idéia de produtividade em pesquisa que se reflete em um excesso de artigos publicados em várias revistas científicas. A contabilização numérica de artigos publicados por investigadores em revistas científicas de reconhecido status acadêmico serve para legitimar acadêmicos nos seus campos de atuação de várias formas. Nesse sentido, sugere-se que o artigo científico assume aspectos de mercadoria como fetiche, segundo a teorização do valor de uso/valor de troca de Marx e do valor de exposição de Benjamin. Ao mesmo tempo, utilizam-se as idéias biológicas de seleção/evolução como elementos metafóricos constitutivos do "darwinismo bibliográfico". Há referências quanto à possibilidade de grande parte das preocupações bibliométricas vigentes servirem como instrumentos de análise econométrica para, sobretudo, orientar e aperfeiçoar análises de custoefetividade em investimentos em pesquisa de várias ordens e tipos sob o ponto de vista de seu retorno econômico.

Artigo de Revista; Publicações Periódicas; Comunicação e Divulgação Científica

\section{Referências}

1. Glanzel W, Leta J, Thijs B. Science in Brazil. Part 1: a macro-level comparative study. Scientometrics 2006; 67:67-86.

2. Coimbra Jr. CEA. Fórum: produção científica e avaliação em Saúde Pública. Cad Saúde Pública 2003; 19:1845-6.

3. Luz MT. Prometeu acorrentado: análise sociológica da categoria produtividade e as condições atuais da vida acadêmica. Physis (Rio J) 2005; 15:39-57.

4. Caponi S, Rebelo F. Sobre juízes e profissões: a avaliação de um campo disciplinar complexo. Physis (Rio J) 2005; 15:59-82.

5. Collins HM. Tantalus and the aliens: publications, audiences, and the search for gravitational waves. Soc Stud Sci 1999; 29:163-97.

6. Gunsalus CK. Ethics: sending out the message. Science 1997; 276:335.

\section{Colaboradores}

Ambos os autores desenvolveram conjuntamente os conteúdos abordados. L. D. Castiel redigiu o artigo.
7. Nuñez-Jover J. La ciencia y la tecnología como procesos sociales. Lo que la educación científica no debería olvidar. Madrid: Organización de Estados Iberoamericanos. http://www.campus-oei.org/ salactsi/nunez06.htm (acessado em 28/Mai/2006).

8. Viqueira JP. Propiedad intelectual versus conocimiento. El debate sobre "acceso abierto". Michoacán: Centro Público de Investigación CONACYT; 2005. http://www.colmich.edu.mx/ relaciones/104/pdf/documento.pdf (acessado em 28/Mai/2006).

9. Hudson-Jones A. Changing traditions of authorship. In: Hudson-Jones A, McLellan F, editors. Ethical issues in biomedical research. Baltimore: Johns Hopkins University Press; 2000. p. 3-29.

10. Gaceta Sanitaria. Normas para autores de Gaceta Sanitaria. http://www.doyma.es/revista/info/pdf/ 138Normas.pdf (acessado em 12/Out/2006). 
11. Sanz-Valero J, Castiel LD, Wanden-Berghe C, Quilis VJ. Internet y la búsqueda de información en Salud Pública: desde la relevancia hacia la "revelancia". Gac Sanit 2006; 20:159-60.

12. Weed DL. Preventing scientific misconduct. Am J Public Health 1998; 88:125-9.

13. Syrett KL, Rudner LM. Authorship ethics. Practical Assessment, Research \& Evaluation 1996; 5(1). http://PAREonline.net/getvn.asp?v=5\&n=1 (acessado em 01/Jun/2006).

14. Hersh WR. Information retrieval: a health and biomedical perspective. 2nd Ed. New York: SpringerVerlag; 2003.

15. Fourez G. A construção das ciências: introdução à filosofia e à ética das ciências. São Paulo: Editora Unesp; 1995.

16. Latour B. Essays on science and society: from the world of science to the world of research? Science 1998; 280:208-9.

17. Acquarone F. Grandes benfeitores da humanidade. Rio de Janeiro: Irmãos Pongetti Editora; 1945.

18. Merton RK. La sociología de la ciencia. Madrid: Alianza Editorial; 1977.

19. Hagstrom WO. El don como principio organizador de la ciencia. In: Barnes B, editor. Estudios sobre sociología de la ciencia. Madrid: Alianza Editorial; 1980. p. 103-18.

20. Stengers I. Quem tem medo das ciências. Ciências e poderes. Rio de Janeiro: Edições Siciliano; 1990.

21. Hackett EJ. Essential tensions: identity, control, and risk in research. Soc Stud Sci 2005; 35:787-826.

22. Coimbra Jr. CEA. Produção científica em saúde pública e as bases bibliográficas internacionais. Cad Saúde Pública 1999; 15:883-8.

23. BMJ. Instructions for authors. http://bmj.bmj journals.com/advice/ (acessado em 12/Out/ 2006).

24. Arranz M. ¿Escribir o publicar? Las reglas del juego. Gac Sanit 2003; 17:90-1.

25. Albert T. Cómo escribir artículos científicos fácilmente. Gac Sanit 2002; 16:354-7.

26. Marx K. O capital - crítica da economia política. Livro I, v. 1. 13a Ed. Rio de Janeiro: Bertrand Brasil; 1989.

27. Benjamin W. A obra de arte na era de sua reprodutibilidade técnica. In: Benjamin W, organizador. Magia e técnica, arte e política. 7ạ Ed. São Paulo: Editora Brasiliense; 1994. p. 165-96.

28. Agamben G. Profanaciones. Barcelona: Anagrama; 2005.

29. Kuhn T. A estrutura das revoluções científicas. 4a Ed. São Paulo: Editora Perspectiva; 1996.

30. Gunn IP. Death of a journal: lost opportunities, new challenges, or both? CRNA 2000; 11:197.
31. Journal of Epidemiology and Community Health JECH: top ten articles of 2005. http://jech.bmj journals.com/misc/topten05.dtl (acessado em 12 / Jun/2006).

32. Sage Journals Online. The 50 most frequently read articles. http://sss.sagepub.com/reports/mfrl.dtl (acessado em 12/Jun/2006).

33. Velho L. Indicadores científicos: aspectos teóricos y metodológicos e impactos en la política científica. In: Martínez E, Albornoz M, organizadores. Indicadores de ciencia y tecnología: estado del arte y perspectivas. Caracas: Nueva Sociedad; 1998. p. 23-51.

34. Mirowski P. Re-engineering scientific credit in the era of globalized information economy. First Monday 2001; 6(1). http://www.firstmonday.org/ issues/issue6_12/mirowski/ (acessado em 12/ Jun/2006).

35. Patsopoulos NA, Ioannidis JPA, Analatos AA. Origin and funding of the most frequently cited papers in medicine: database analysis. BMJ 2006; 332:1061-4.

36. Mirowski P, van Horn R. The contract research organization and the commercialization of science. Soc Stud Sci 2005; 35:503-48.

37. Porta M, Copete JL, Fernandez E, Alguacil J, Murillo J. Mixing journal, article, and author citations, and other pitfalls in the bibliographic impact factor. Cad Saúde Pública 2003; 19:1847-62.

38. Martin B. Dissent and heresy in medicine: models, methods and strategies. Soc Sci Med 2004; 58: 713-25.

39. Fernandez E, Plasencia A. Contamos contigo: ¿contamos también con tus citas? Gac Sanit 2002; 16:288-90

40. Research Services Group of Thomson Scientific. Essential science indicators. http://in-cites.com/ rsg/esi/ (acessado em 01/Jun/2006).

41. Latour B. Woolgar S. Laboratory life: the construction of scientific facts. Princeton: Princeton University Press; 1986.

42. McSherry C. Who owns academic work? Battling for control of intellectual property. Cambridge: Harvard University Press; 2001.

43. Peter I. The beginnings of the Internet. http://www. nethistory.info/History\%20of\%20the\%20Internet/ beginnings.html (acessado em 31/Mai/2006).

44. Alvarenga L. Bibliometria e arqueologia do saber de Michel Foucault: traços de identidade teóricometodológica. Ciênc Inf 1998; 27:253-61.

45. Bauman Z. Wasted lives: modernity and its outcasts. London: Blackwell Publishing; 2004.

Recebido em 06/Jun/2006

Aprovado em 01/Jun/2007 